\title{
Experimental determination of tensile properties of okra, sisal and banana fiber reinforced polyester composites
}

\author{
N. Srinivasababu ${ }^{1 *}$, K. Murali Mohan $\mathrm{Rao}^{2}$ and J Suresh Kumar ${ }^{3}$ \\ ${ }^{1}$ Dept. of Mech. Engg,, PVP Siddhartha Inst. of Technol., Vijayawada; ${ }^{2}$ Sri Viveka Inst.of Technol., Madalavarigudem; \\ ${ }^{3}$ Dept .of Mech. Eng., JNT Univ. H, Hyderabad, India \\ *cnjlms22@yahoo.co.in
}

\begin{abstract}
Increasing the needs for different engineering applications invite the development of new materials. In the present research new natural fiber okra was introduced for the preparation of okra fiber reinforced polyester (FRP) composites. Already established fibers sisal and banana were also extracted for the preparation of sisal and banana FRP composites and to determine tensile properties. The tensile properties of okra FRP composites were compared with sisal and banana FRP composites. Hand lay-up technique was used for the preparation of composites. Chemically treated okra fiber reinforced polyester composites at maximum volume fraction showed tensile strength, modulus of $154.17 \%$, $114.13 \%$ and specific tensile strength and modulus of $12.26 \%, 129.82 \%$ higher than that of the pure polyester specimen, respectively.
\end{abstract}

Keywords: Okra fiber, hand-lay up, density, tensile strength, tensile modulus, specific tensile strength, specific tensile modulus.

\section{Introduction}

In tropical regions of India, there are large varieties of regenerative plants and trees with fiber content. Some of them are cultivated over the generations and some are wild plants, trees and creepers that grow in forests and woods. It is an established fact that any material in its fibrous form is stronger than in bulk form. These strong fibers are used to reinforce the weak materials.

Tensile testing of untreated jute fabric-reinforced polyester composites was studied and the average values of UTS, initial tangent modulus for these composites are $60 \mathrm{MPa}, 7 \mathrm{GPa}$ (Munikenche Gowda et al., 1999). A classical volumetric method using ethanol as a solvent is used for density determination of flax fiber (Baley, 2002). Effect of compounding technique on mechanical properties of flax fiber/pp composites is determined. In general extruded samples showed slightly lower tensile moduli than those molded in the internal mixture (Arbelaiz et al., 2005).

The tensile strength of bagasse fibercomposites increased from 16.5 to $23.5 \mathrm{MPa}$ with increase in fiber content (wt \%) from 20 to $65 \%$. However the tensile strength decreased to $20 \mathrm{MPa}$ despite increase in fiber content to $75 \%$. The effects of alkali treatments (1, 3, 5\%) of bagasse fibers on the tensile strength was examined using the treated fiber (65\%) composites. The tensile strength of the alkali treated fiber composites at $20 \%$ fiber content was 18.6 MPa against 16.5 MPa for the untreated fiber composites. For alkali treated bagasse fiber composites Tensile strength at fiber $65 \mathrm{wt} \%$ is 26.77 $\mathrm{MPa}$ which is higher than untreated fiber (Cao et al., 2006).

Tensile strength of the untreated LF-PP composites containing $15 \mathrm{wt} \%$ LF decreased from 33 to $19.5 \mathrm{MPa}$ which corresponds to the $41 \%$ decrease (Demir et al., 2006). For modified filler (Epoxy based materials) the stress at break is $1.76 \pm 0.13 \mathrm{MPa}$, modified filler unsaturated polyester based materials $0.72 \pm 0.06 \mathrm{MPa}$ (Hamid Kaddami et al., 2006). The mechanical properties of flax / polypropylene compounds, manufactured both with a batch kneading and an extrusion process were determined and compared with the properties of NMT composites (Harriette L. Bos et al., 2006). Interfacial strength does not increase with alkali treatment. In the case of acetylated fibers, the interfacial strength decreases with treatment, showing the lower adhesion between fibers and matrix (Vera A Alvarez \& Analia Vazquez 2006). Rice straw composites were formulated up to the volume fraction of $40 \%$ and mean tensile strength is $46 \mathrm{MPa}$ (Ratna Prasad et al., 2007). The tensile strength and modulus of chemically extracted elephant grass fiber composites have increased by approximately 1.45 times to those of elephant grass fiber composite extracted by retting (Murali Mohan Rao et al., 2007). Arecanut fiber reinforced composites at a volume fraction of 0.39 , resulting in mean tensile strength and modulus of 24 and $40 \%$ more in comparison to those of plain polyester (Ecamalon 4411) respectively (Ratna Prasad et al., 2006). The tensile strength of the fiber before and after alkali treatment was determined and it was found that tensile strength of the fiber decreased from 489.9 to $243.6 \mathrm{MPa}$ after treatment in $6 \% \mathrm{NaoH}$ for 5 $\mathrm{h}$ at room temperature (Suchada Tragoonwichian et al., 2007). Tensile strength and moduli of the LLDPE based coir fiber composites increased with increase in fiber loading (Arup Choudary et al., 2007). Banana FRP composites having fiber length of $30 \mathrm{~mm}$ and a fiber content of $40 \mathrm{vol} \%$ showed the maximum tensile strength (Sreekumar et al., 2008). The highest tensile strength values has obtained for an intimate mixture of banana and glass fibers has been obtained for composite samples prepared from interleaving layers of banana fiber and glass fiber (Seena Joseph et al., 2008). All composites showed an increase in tensile strength with the addition of MAPP (Beckermann \& Pickering, 2008). The effect of chemical treatment i.e. bleaching, alkalization and graft copolymerization on the morphology changes of okra bast fiber has been investigated by
Research article

CIndian Society for Education and Environment (iSee)
"Natural fiber reinforced polyester" http://www.indjst.org
Srinivasababu et al. Indian J.Sci.Technol. 
means of IR spectroscopy, SEM, water absorption and tensile measurements (Arifuzzaman Khan et al., 2009).

In the present research okra (Abelmoschus esculentus; synonym "Hibiscus esculentus L".) fiber is taken for the preparation of composites.

\section{Experimental work \\ Fiber extraction}

New fiber considered in the present research was extracted by the following procedure. The removed okra stems were placed in a pit containing stagnant mud water for 6 days at ambient conditions. On $7^{\text {th }}$ day the stems were washed with sufficient quantity of water till complete pulp was detached from fiber. Then the fiber was dried for 7 days at ambient conditions. The fiber obtained was $5 \mathrm{ft}$. to $7 \mathrm{ft}$. long (Fig. 1).

Sisal and banana fiber was obtained from Vishakapatnam, Jagarlamudi, Guntur (Dt.), Andhra Pradesh respectively.

Matrix. Ecmalon 4413 general purpose unsaturated polyester resin of medium reactivity is used in the present investigation. The properties of the liquid resin are tested in accordance with IS 6746-1994 and the values can vary within tolerances mentioned therein Table 1.

The resin contains a volatile monomer with a flash point at $32^{\circ} \mathrm{C}$ and is of moderate fire hazard.

Chemical treatment (CT): Extracted hybrid okra fiber was chemically treated to investigate the variation in the tensile properties before and after treatment by the improvement of interface between fiber and matrix. The extracted okra fiber was treated with $0.125 \mathrm{M} \mathrm{NaOH}$ solution for 45 minutes. Fiber pre treated with sodium hydroxide was treated with $0.006327 \mathrm{M} \mathrm{KMnO}_{4}$ solution in presence of $0.00375 \mathrm{M} \mathrm{H}_{2} \mathrm{SO}_{4}$ for a period of 5 minutes.

Fiber moisture removal. The fiber was placed in a NSW143 Oven Universal (Super deluxe model), supplied by Narang Scientific Works Private Limited, New Delhi, India, at a temperature of $70^{\circ} \mathrm{C}$ for 1 hour. Then fiber was allowed to cool to room temperature. The fiber was then taken out for the preparation of composite specimen.

Fiber density determination: The density of okra, sisal and banana fibers was determined by PICNOMETRY procedure. The fibers were dried in an oven for a period of 24 hours at a temperature of $50^{\circ} \mathrm{C}$. The specific gravity bottle (SPG) / Picnometer was dried completely and weighed with its cap tightly screwed $\left(m_{1}\right)$. The cap was marked initially, so that the cap was screwed by the same amount each time. The cap was unscrewed and dried fibers from the oven were placed in it and weighed again $\left(m_{2}\right)$. The SPG bottle having fiber in it was filled with kerosene

\begin{tabular}{|c|c|c|c|c|c|}
\multicolumn{7}{|c}{ Table 1. Properties of liquid resin } \\
\hline Appearance & Clear & $\begin{array}{c}\text { Specific } \\
\text { gravity } \\
\left(25 / 25^{\circ} \mathrm{C}\right)\end{array}$ & 1.13 & $\begin{array}{c}\text { Volatiles } \\
@ ~ 150^{\circ} \mathrm{C} \\
(\%)\end{array}$ & 35 \\
\hline $\begin{array}{c}\text { Viscosity @ } \\
25^{\circ} \mathrm{C}\end{array}$ & $\begin{array}{c}500 \\
\begin{array}{c}\text { (Brookfield } \\
\text { viscometer }\end{array}\end{array}$ & $\begin{array}{c}\text { Acid value } \\
(\mathrm{mgKOH} / \mathrm{g})\end{array}$ & 25 & $\begin{array}{c}\text { Gel time } \\
\text { @ } 25^{\circ} \mathrm{C} \\
\text { (minutes) }\end{array}$ & 20 \\
\hline
\end{tabular}

completely up to the specified mark and weighed it again by wiping the outer surface of the bottle with cotton cloth $\left(m_{3}\right)$. Now the SPG bottle was completely filled with kerosene up to the mark with out fiber (i.e. take out the fiber from the bottle) and weighed $\left(\mathrm{m}_{4}\right)$. The weighing was done using Shimadzu, Electronic Balance, Type BL-220H, readability $0.001 \mathrm{~g}$. The specific gravity of the fiber was determined using the formula:

$$
\mathrm{G}=\frac{\mathrm{m}_{\mathrm{S}}}{\mathrm{m}_{\mathrm{S}}+\mathrm{m}_{4}-\mathrm{m}_{3}}
$$

Where

$\mathrm{m}_{\mathrm{s}}=$ mass of fiber in grams $\left(\mathrm{m}_{2}-\mathrm{m}_{1}\right)$

$\mathrm{m}_{1}=$ mass of empty picnometer in grams

$\mathrm{m}_{2}=$ (mass of picnometer + dry fiber) in grams

$\mathrm{m}_{3}=$ (mass of picnometer + dry fiber + kerosene) in grams

$\mathrm{m}_{4}=$ (mass of picnometer + kerosene) in grams

Determination of fiber volume fraction: The volume fraction of fiber was calculated by a method which enables the rule of mixtures and analysis of measured composite properties. The method involves measuring the density of the composite $\left(\rho_{C}\right)$ of mass $M_{C}$ at a given mass fraction of the resin $M_{R}$. Volume fraction of resin $\left(V_{R}\right)$ was calculated using the formula

$$
V_{R}=\frac{M_{R} \times \rho_{C}}{M_{C} \times \rho_{R}}
$$

Where $\rho_{R}=$ density of resin in $\mathrm{kg} / \mathrm{m}^{3}$

Then the fiber volume fraction was determined by the relation

$$
\mathrm{V}_{\mathrm{F}}=1-\mathrm{V}_{\mathrm{R}}
$$

Tensile properties characterization: The specimens were prepared according to ASTM D 5083-02 using hand-lay up and was tested using Electronic Tensometer, supplied by Kudale Instruments Pvt. Ltd., Pune, India.

\section{Results and discussion}

The density of the okra, sisal, banana fiber reinforced polyester composites decreases with increasing volume fraction of fiber. Because the fiber density is lower than that of the matrix there by the density of composite decreases with increase in fiber content.

Fig. 2 shows the variation of tensile strength with increase in percentage volume fraction of fiber. Tensile strength of untreated okra FRP composites increased linearly up to the volume fraction of 20.4 $\%$ and was 2.34 times higher than that of the matrix where as chemically treated (CT) Indian J.Sci.Technol. 
okra fiber composites tensile strength was $6.43 \%, 154.17$ $\%$ higher than untreated okra fiber composites and matrix respectively. For same percentage volume fraction of fiber the tensile strength of the composites increasing in the order of banana, sisal, okra and chemically treated okra. The tensile strength is more than rice straw and Arecanut fiber reinforced polyester composites reported by the authors in references 9 and 11 respectively.

The effect of percentage volume fraction of fiber with specific tensile strength is shown in Fig. 3 . The specific tensile strength of the composites increasing in the order
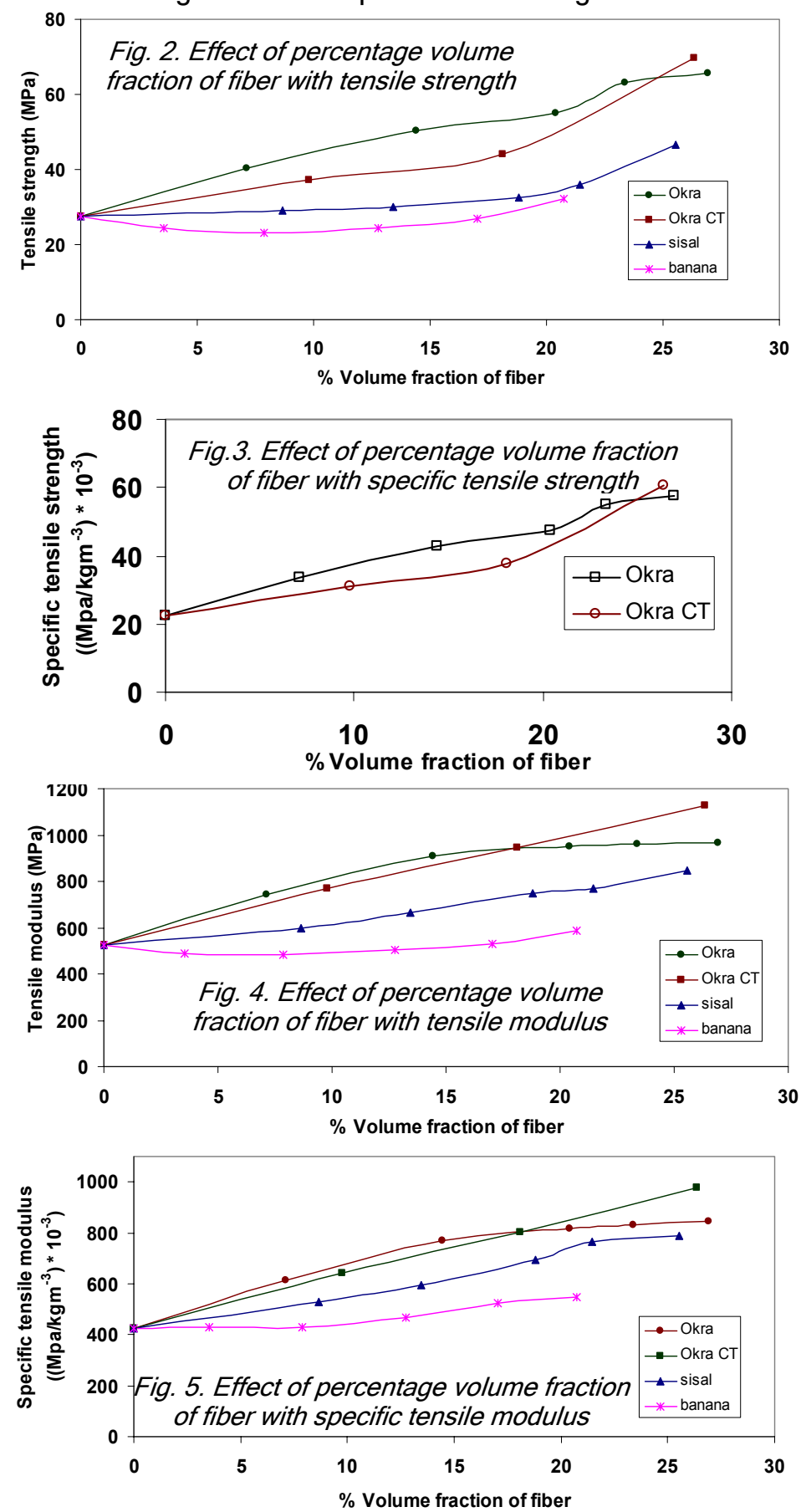

of banana, sisal, okra, chemically treated okra at the same percentage volume fraction of fiber. Specific tensile strength of okra untreated and treated FRP composites increases with increasing volume fraction of fiber linearly up to the volume fraction of $20.4 \%$. The specific tensile strength of chemically treated okra FRP composites is 1.11times higher than untreated composites.

The increase in stiffness in okra FRP composites was due to the increase in fiber content. The effect of percentage volume fraction of fiber with tensile modulus is shown in Fig. 4. Chemically treated okra fiber reinforced composites tensile modulus is $1124.73 \mathrm{MPa}$ at volume fraction of $26.36 \%$ which was higher than untreated okra fiber reinforced composites. The tensile modulus of banana fiber reinforced polyester composites was not appreciably increased. Chemical treatment improved the interface strength between fiber and matrix and the tensile modulus increased linearly for okra fiber reinforced polyester composites.

The effect of percentage volume fraction of fiber with specific tensile modulus was shown in Fig. 5. Specific tensile modulus of chemically treated okra FRP composites was 1.02 times higher than untreated okra fiber reinforced composites. Specific tensile modulus of the composites increased in the order of banana, sisal, okra and chemically treated okra at the same percentage volume fraction of fiber. Specific tensile modulus of okra FRP composites increased linearly from the volume fraction of $20.4 \%$ to $26.93 \%$.

\section{Conclusions}

- Okra natural fiber can be extracted form the okra stems through aerobic decomposition in mud water manually. The optimum time period for extraction of fiber was 6 days.

- Chemical extraction enhanced the tensile strength and modulus, which is clear from the graphs.

- Hand lay-up technique can be used for the preparation of composite specimens successfully.

- Okra individual fiber reinforced composites after chemical treatment is better choice than other composites studied because it shows highest tensile strength and tensile modulus.

- Specific tensile strength is also highest for chemically treated okra fiber reinforced polyester composites.

\section{References}

1. Arbelaiz A, Fernandez B, Cantero G, Llano-Ponte R, Valea A and Mondragon I (2005) Mechanical properties of flax fiber/poly propylene composites. Influence of fiber/matrix modification and glass fiber hybridization. Composites Part A. 36, 1637-1644.

2. Arifuzzaman Khan GM, Shaheruzzaman Md., Rahman $\mathrm{MH}$, Abdur Razzaque SM, Sakinul Islam Md. and Shamsul Alam Md. (2009) Surface modification of okra
Research article

CIndian Society for Education and Environment (iSee)
"Natural fiber reinforced polyester" http://www.indjst.org
Srinivasababu et al. Indian J.Sci.Technol. 
bast fiber and its Physico-chemical characteristics. Fibers \& Polymers. 1, 65-70.

3. Arup Choudary, Sandeep Kumar and basudam adhikari (2007) Recycled milk pouch and virgin LDPE/Linear LDPE based coir composites. J. App. Poly. Sci. 106, 775-785.

4. Baley C (2002) Analysis of flax fibers tensile behaviour and analysis of the tensile stiffness increase. Composites Part A. 33, 939-348.

5. Beckermann GW and Pickering K L (2008) Engineering and evaluation of hemp fiber reinforced poly propylene composites: Fiber treatment and matrix modification Composites Part A. 39, 979-988.

6. Cao Y, Shibata S and Fukumoto I (2006) Mechanical properties of biodegradable composites reinforced with bagasse fiber before and after alkali treatments. Composites Part A. 37, 423-429.

7. Demir H, Atikler U, Balkose D and Tihminlioglu (2006) The effect of fiber surface treatments on tensile and water sorption properties of polypropylene-luffa fiber composites. Composites Part A. 37, 447-456.

8. Hamid Kaddami, Alain Dufresne, Bertine Khelifi, Abdelkader Bendahou, Moha Taourirte, Mustapha Raihane, Nathalie Issartel, Henry Sautereau, JeanFrancois Gerard, Noureddine Sami (2006) Short palm tree fibers - Thermoset matrices and composites. Composites Part A. 37, 1413-1422.

9. Harriette L. Bos, Jorg Mussig, Martien JA and Van den Oever (2006) Mechanical properties of short-flax-fiber reinforced compounds. Composites Part A. 37, 15911604.

10. Munikenche Gowda T, Naidu ACB and Rajput Chhaya (1999) Some mechanical properties of untreated jute fabric-reinforced polyester composites. Composites Part A. 30, 277-284.

11. Murali Mohan Rao K, Ratna Prasad AV, Ranga Babu MNV, Mohan Rao K and Gupta AVSSKS (2007) Tensile properties of elephant grass fiber reinforced polyester composites. J. Mat. Sci. 42, 3266-3272.

12.Ratna Prasad AV, Murali Mohan Rao K and Anil Kumar M (2007) Flexural properties of rice straw reinforced polyester composites. Indian J. Fiber \& Textile Res. 32, 399-403.

13. Ratna Prasad AV, Murali Mohan Rao K, Mohan Rao K and Gupta AVSSKS (2006) Effect of fiber loading on mechanical properties of arecanut fiber reinforced polyester composites. Natl. J. Tech. 2, 56-62.

14. Seena Joseph, Sreelekha M S, peter Koshy and Sabu Thomas (2008) Mechanical properties and water sorption behaviour of phenol formaldehyde hybrid composites reinforced with banana fiber and glass fiber, J. App. Poly. Sci., 109, 1439-1446.

15. Sreekumar PA, Pradesh Albert, Unnikrishnan G, Kuruvilla Joseph and Sabu Thomas (2008) Mechanical and water sorption studies of ecofriendly banana fiber reinforced polyester composites fabricated by RTM. J. App. Poly. Sci, 109, 1547-1555.
Vol.2 No. 7 (July 2009)

ISSN: 0974- 6846

16.Suchada Tragoonwichian, Nantaya Yanumet and Hatsuo Ishida (2007) Effect of fiber surface modification on the mechanical properties of sisal fiber reinforced benzoxazine/epoxy composites based on aliphatic diamine benzoxazine. J. App. Poly. Sci. 106, 29252935.

17.Vera A Alvarez and Analia Vazquez (2006) Influence of fiber chemical modification procedure on the mechanical properties and water absorption of MaterBiY/sisal fiber composites. Composites Part A. 37, 16721680. 